$\pm 77.0 \%$ at 12 month. The rate of increased LS-BMD from baseline to 6 and 12 months were $8.6 \pm 8.0 \%, 12.5 \pm 11.1 \%$ and TH-BMD were $4.3 \pm 5.0 \%, 6.8 \pm 6.9 \%$ (Fig. 1,2 ) Conclusion: Clinical efficacy of ROMO for RA-OP was extremely effective and has the high potential to be an important option in the treatment of RA-OP.



Fig.1: The rate of increased LS-BMD from baseline to 12 month

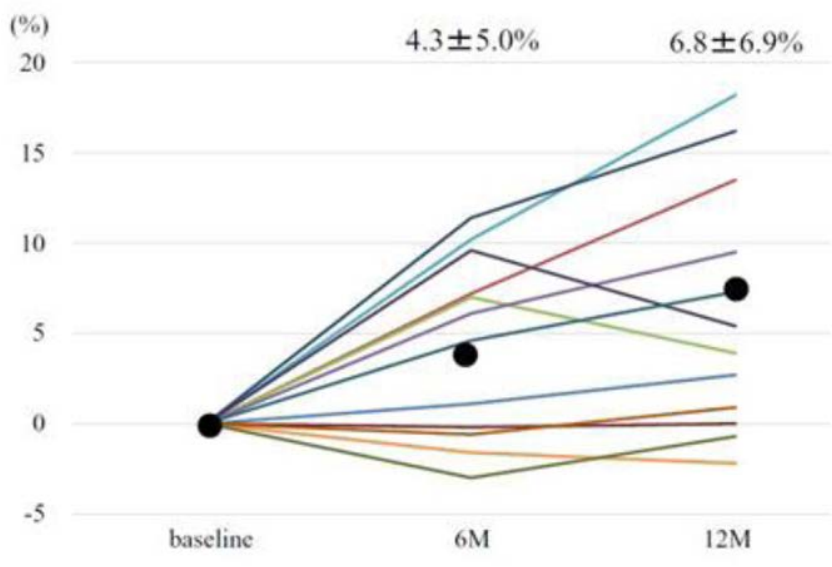

Fig.2: The rate of increased TH-BMD from baseline to 12 month

Disclosure of Interests: None declared

DOI: 10.1136/annrheumdis-2021-eular.3462

\begin{tabular}{|l|l}
\hline OP0108 & LORECIVIVINT (SM04690), AN INTRA-ARTICULAR, \\
SMALL-MOLECULE CLK2/DYRK1A INHIBITOR \\
THAT MODULATES THE WNT PATHWAY, PROVIDED \\
CARTILAGE-PROTECTIVE EFFECTS IN AN ANIMAL \\
MODEL OF POST-TRAUMATIC OA
\end{tabular}

T. Seo ${ }^{1}$, V. Deshmukh ${ }^{1}$, Y. Yazici' ${ }^{2}{ }^{1}$ Samumed, LLC, Biology, San Diego, United States of America; ${ }^{2}$ Samumed, LLC, Chief Medical Officer, San Diego, United States of America

Background: Osteoarthritis $(\mathrm{OA})$ is characterized by increased cartilage thinning, bone remodeling, and inflammation. Post-traumatic OA, which develops after acute direct trauma to the joints, accounts for approximately $12 \%$ of all OA cases. ${ }^{1}$ Current therapeutic options focus on alleviating symptoms and pain rather than disease modification. Lorecivivint (LOR; SM04690), an intra-articular (IA), small-molecule CLK2/DYRK1A inhibitor that modulates the Wnt pathway, has been shown in animal studies to induce chondrogenesis, protect cartilage, and reduce inflammation and, thereby, improve joint health. ${ }^{2}$

Objectives: A single IA LOR injection was evaluated in a rat model of knee instability to determine its protective and regenerative effects when injected at different timepoints after induction of post-traumatic OA.
Methods: Knee instability/post-traumatic OA was surgically induced in rats by combining anterior cruciate ligament transection with partial medial meniscus transection (ACLT+pMMx). LOR $(0.3 \mathrm{ug})$ or vehicle was injected into the IA space of the damaged knee at 2, 3, or 4 weeks after induction of OA. OA-induced ( $n=10 /$ group) or sham-operated (surgery without $A C L T+p M M x ; n=5 / g r o u p$ ) rats were sacrificed at the injection timepoint (baseline) or 12 weeks following LOR/vehicle injection (study conclusion). Histological grades were evaluated using the summed OARSI scores (stage and grade of cartilage damage) ${ }^{3}$ of the anterior and posterior medial femoral condyle (MFC) and medial tibial plateau (MTP). Weight distribution analysis was performed using an incapacitance meter at several timepoints. Statistical analysis was performed using one-way ANOVA with Dunnett's multiple comparison test.

Results: ACLT+pMMx surgeries led to increased OARSI scores in rats compared with sham surgeries by 2 weeks. LOR treatment at Weeks 2, 3, and 4 led to significant decreases $(P<0.05)$ in total joint OARSI scores (Table 1$)$ at the end of the study compared with vehicle treatment. Rats treated with LOR for 12 weeks and rats at injection baseline had similar OARSI scores, suggesting that LOR treatment arrested the progression of cartilage damage. Significant improvements $(P<0.05)$ were also observed in the weight distribution of LOR treated rats in the 3- and 4-week groups at 6 and 12 weeks after their respective IA injections compared with vehicle-treated rats.

Table 1. OARSI scores

\begin{tabular}{|c|c|c|c|c|}
\hline Week-2 injection & $\begin{array}{l}\text { Sham-operated } \\
\begin{array}{c}\text { (14 weeks after } \\
\text { surgery) }\end{array}\end{array}$ & $\begin{array}{l}\text { Baseline (BL) } \\
\text { (2 weeks after } \\
\text { surgery) }\end{array}$ & $\begin{array}{c}\text { Vehicle } \\
\text { (12 weeks after } \\
\text { injection) }\end{array}$ & $\begin{array}{c}\text { LOR } \\
\text { (12 weeks after } \\
\text { injection) }\end{array}$ \\
\hline Total score & 5.99 & 19.17 & 31.36 & 19.19 \\
\hline $\begin{array}{l}\text { SEM } \\
P \text { value versus BL } \\
P \text { value versus } \\
\quad \text { vehicle }\end{array}$ & 1.07 & 1.55 & 2.48 & $\begin{array}{c}1.81 \\
0.9999 \\
0.0004\end{array}$ \\
\hline Week-3 injection & $\begin{array}{l}\text { Sham-operated } \\
\begin{array}{c}\text { (15 weeks after } \\
\text { surgery) }\end{array}\end{array}$ & $\begin{array}{l}\text { Baseline (BL) } \\
\text { (3 weeks after } \\
\text { surgery) }\end{array}$ & $\begin{array}{c}\text { Vehicle } \\
\text { (12 weeks after } \\
\text { injection) }\end{array}$ & $\begin{array}{c}\text { LOR } \\
\text { (12 weeks after } \\
\text { injection) }\end{array}$ \\
\hline Total score & 6.09 & 23.17 & 30.45 & 21.20 \\
\hline $\begin{array}{l}\text { SEM } \\
P \text { value versus } B L \\
P \text { value versus } \\
\quad \text { vehicle }\end{array}$ & 1.25 & 1.36 & 1.42 & $\begin{array}{c}1.00 \\
0.4522 \\
0.0001\end{array}$ \\
\hline Week-4 injection & $\begin{array}{l}\text { Sham-operated } \\
\begin{array}{c}16 \text { weeks after } \\
\text { surgery })\end{array}\end{array}$ & $\begin{array}{l}\text { Baseline (BL) } \\
\text { (4 weeks after } \\
\text { surgery) }\end{array}$ & $\begin{array}{c}\text { Vehicle } \\
\text { (12 weeks after } \\
\text { injection) }\end{array}$ & $\begin{array}{c}\text { LOR } \\
\text { (12 weeks after } \\
\text { injection) }\end{array}$ \\
\hline Total score & 6.97 & 16.88 & 24.95 & 18.63 \\
\hline $\begin{array}{l}\text { SEM } \\
P \text { value versus } B L \\
P \text { value versus } \\
\quad \text { vehicle }\end{array}$ & 1.32 & 1.04 & 1.74 & $\begin{array}{c}1.61 \\
0.6257 \\
0.0111\end{array}$ \\
\hline
\end{tabular}

Conclusion: LOR exhibited cartilage-protective effects and slowed disease progression in the ACLT+pMMx model in vivo and, therefore, has potential as a structure-modifying treatment for $O A$.

REFERENCES:

[1] Brown TD, et al. J Orthop Trauma. 2006.

[2] Deshmukh V, et al. Osteoarthr Cartil. 2019.

[3] Pritzker KPH, et al. Osteoarthr Cartil. 2006.

Disclosure of Interests: Tim Seo Shareholder of: Samumed, LLC, Employee of: Samumed, LLC, Vishal Deshmukh Shareholder of: Samumed, LLC, Employee of: Samumed, LLC, Yusuf Yazici Shareholder of: Samumed, LLC, Employee of: Samumed, LLC

DOI: 10.1136/annrheumdis-2021-eular.2237

\section{OP0109 CARTILAGE LESIONS OF THE KNEE: GAGCEST IMAGING AT 3 T MRI AND INTRAOPERATIVE VALIDATION}

M. Pachowsky ${ }^{1}$, S. Söllner ${ }^{2}$, A. Kleyer ${ }^{3}$, G. Welsch ${ }^{4}$, G. Schett ${ }^{3}{ }^{1}$ University Hospital of Erlangen, Erlangen, Germany, Department of Internal Medicine 3 - Rheumatology and Immunology, Department of Trauma and Orthopaedic Surgery and Friedrich-Alexander-University Erlangen-Nürnberg (FAU), Germany, Erlangen, Germany; ${ }^{2}$ University Hospital of Erlangen, Germany, Department of Trauma and Orthopaedic Surgery, Erlangen, Germany; ${ }^{3}$ University Hospital of Erlangen, Erlangen, Germany, Department of Internal Medicine 3 - Rheumatology and Immunology, and Friedrich-Alexander-University Erlangen-Nürnberg (FAU), Germany, Erlangen, Germany; ${ }^{4}$ University Hospital Hamburg-Eppendorf, Hamburg, Germany, UKE Athleticum, Hamburg, Germany

Background: Morphological Magnetic Resonance Imaging (MRI) has become the accepted diagnostic tool for non-invasive evaluation of cartilage lesions ${ }^{1}$. Emerging 
techniques including chemical exchange saturation transfer (CEST) can be used to visualize microstructural and biochemical changes to the cartilage matrix even before morphological damage is visible ${ }^{2,3}$. CEST is a promising technique based on detecting the chemical exchange between bulk water protons and protons bound to solutes. This technique renders the possibility to function as a biomarker for glycosaminoglycan (GAG/gag) content for instance in cartilage of joints.

Objectives: The aim of the study was to compare glycosaminoglycan chemical exchange saturation transfer (gagCEST) of knee cartilage with intraoperative results for the assessment of early osteoarthritis (OA) and to define gagCEST values for the differentiation between healthy and degenerated cartilage.

Methods: Patients with cartilage lesions or moderate OA were preoperatively examined using 3T Magnetic Resonance Imaging (MRI). In this prospective study, regions of interest (ROIs) were examined by a sagittal gagCEST analysis and a morphological high-resolution three-dimensional, fat-saturated proton-density space sequence. Cartilage lesions were identified arthroscopically, graded by the International Cartilage Repair Society (ICRS) score in 42 defined ROls per patient and consecutively compared with mean gagCEST values using analysis of variance and Spearman's rank correlation test. Receiver operating characteristics (ROC) curves were applied to identify gagCEST threshold values to differentiate between the ICRS grades.a

Results: Twenty-one patients with cartilage lesions or moderate OA were examined. The imaging assessment consisted of a total of 882 ROls which were examined and graduated in ICRS score 0 (67.3\%), 1 (25.2\%), $2(6.2 \%)$ and the merged ICRS 3 and 4 (1.0\%). gagCEST values decreased with increasing grade of cartilage damage with a negative correlation between gagCEST values and ICRS scores. A gagCEST value threshold of $3.55 \%$ was identified to differentiate between ICRS score 0 (normal) and all other grades.

Conclusion: Conclusions. gagCEST reflects the content of glycosaminoglycan and might provide a diagnostic tool for the detection of early knee-joint cartilage damage and for the non-invasive subtle differentiation between ICRS grades by MRI even at early stages in clinical practice.

REFERENCES:

[1] Crema, M.D., M.H. Nogueira-Barbosa, F.W. Roemer, M.D. Marra, J. Niu, F.A. Chagas-Neto, et al., Three-dimensional turbo spin-echo magnetic resonance imaging (MRI) and semiquantitative assessment of knee osteoarthritis: comparison with two-dimensional routine MRI. Osteoarthritis Cartilage, 2013. 21(3): p. 428-33.10.1016/j.joca.2012.12.011

[2] Eagle, S., H.G. Potter and M.F. Koff, Morphologic and quantitative magnetic resonance imaging of knee articular cartilage for the assessment of post-traumatic osteoarthritis. J Orthop Res, 2017. 35(3): p. 412-423.10.1002/jor.23345

[3] Liebl, H., G. Joseph, M.C. Nevitt, N. Singh, U. Heilmeier, K. Subburaj, et al., Early T2 changes predict onset of radiographic knee osteoarthritis: data from the osteoarthritis initiative. Ann Rheum Dis, 2015. 74(7): p. 1353-9.10.1136/ annrheumdis-2013-204157

Disclosure of Interests: None declared

DOI: 10.1136/annrheumdis-2021-eular.1822

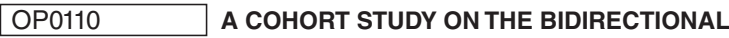 RELATIONSHIP BETWEEN PERIODONTITIS AND OSTEOARTHRITIS OVER A 15-YEAR FOLLOW-UP}

K. S. K. MA ${ }^{1}$, E. Thota ${ }^{1}$, T. Van Dyke ${ }^{2} .{ }^{1}$ National Taiwan University, Taipei, Taiwan, ROC, Department of Life Science, Taipei, Taiwan, Republic of China; ${ }^{2}$ Forsyth Institute, Cambridge, Center for Clinical and Translational Research, Boston, United States of America

Background: Recently, osteoarthritis has been proposed to be driven by complement-mediated inflammatory cascades. That is, in addition to the conventional degenerative model, our knowledge of osteoarthritis pathogenesis has been expanded with an inflammation-dependent theory.

Objectives: To identify the relationship between osteoarthritis and periodontitis. Methods: 144,788 periodontitis patients and 144,788 propensity score-matched controls without history of periodontitis were enrolled in this cohort study. A Cox proportional hazard model was used to estimate the risk of osteoarthritis. Survival analysis was utilized to assess the time-dependent effect of periodontitis on osteoarthritis. Age and gender were stratified to identify susceptible subgroups. A symmetrical case-control analysis was designed to determine the relationship between periodontitis and history of osteoarthritis.

Results: Patients with periodontitis had higher risk of osteoarthritis ( $\mathrm{HR}=1.15$, $95 \% \mathrm{Cl}=1.12-1.17, \mathrm{P}<0.001)$ and severe osteoarthritis that led to total knee/hip replacement $(\mathrm{HR}=1.12,95 \% \mathrm{Cl}=1.03-1.21, \mathrm{P}<0.01)$ than controls, which was time-dependent (log-rank test $P<0.01$ ). The effect of periodontitis on osteoarthritis was significant in both genders and age subgroups over 30 years old (all $\mathrm{P}<0.001)$. Among them, females $(\mathrm{HR}=1.27,95 \% \mathrm{Cl}=1.13-1.42, \mathrm{P}<0.001)$ and patients aged over $51(\mathrm{HR}=1.21,95 \% \mathrm{Cl}=1.10-1.33, \mathrm{P}<0.001)$ with periodontitis were predisposed to severe osteoarthritis that led to total knee/hip replacement. In addition, periodontitis patients were more likely to have a history of osteoarthritis $(\mathrm{OR}=1.11,95 \% \mathrm{Cl}=1.06-1.17, \mathrm{P}<0.001)$.
Conclusion: These findings suggest a bidirectional relationship between osteoarthritis and periodontitis. Patients with periodontitis presented with a higher risk of osteoarthritis, including severe osteoarthritis that led to total knee/ hip replacement. Likewise, periodontitis was more likely to develop following osteoarthritis.

\section{REFERENCES:}

[1]Wang Q, Rozelle AL, Lepus CM, et al. Identification of a central role for complement in osteoarthritis. Nat Med 2011;17:1674-9. Temoin S, Chakaki A, Askari A, et al.

[2] Identification of oral bacterial DNA in synovial fluid of patients with arthritis with native and failed prosthetic joints. J Clin Rheumatol 2012;18:117-21.

Disclosure of Interests: None declared

DOI: 10.1136/annrheumdis-2021-eular.3852

\section{OP0111 \\ PLASMA PROTEOMICS IDENTIFIES CRTAC1 AS BIOMARKER FOR OSTEOARTHRITIS SEVERITY AND} PROGRESSION

I. Szilagyi ${ }^{1,2}$, C. Vallerga ${ }^{3}$, J. H. Waarsing ${ }^{4}$, D. Schiphof ${ }^{2}$, S. M. A. BiermaZeinstra $^{2}$, J. Van Meurs ${ }^{3}$. ${ }^{1}$ Erasmus MC, General Practice, Rotterdam, Netherlands; ${ }^{2}$ Erasmus University Medical Center, General Practice, Rotterdam, Netherlands; ${ }^{3}$ Erasmus University Medical Center, Internal Medicine, Rotterdam, Netherlands; ${ }^{4}$ Erasmus University Medical Center, Orthopedics, Rotterdam, Netherlands

Background: Accurate biomarkers for diagnosis and prediction of osteoarthritis $(\mathrm{OA})$ are needed. In addition, biomarkers have the potential to serve as a measure of the different pathological processes underlying OA. Here, we report on a proteomics screen targeted at two important pathways thought to underlie the etiology of OA: the inflammation and metabolic pathways.

Objectives: The aim of this study was to identify a robust biomarker for OA severity and progression

Methods: We used data from the Rotterdam Study, a population based prospective study with participants aged 45 and older. The participants in this study underwent blood measurement at baseline and radiographic measurements at baseline as well as after a mean follow-up time of 5 years. We measured 184 proteins (inflammation and cardiometabolic panel) in plasma from 3,517 participants in the Rotterdam Study using the Olink platform.

We estimated the association for all available proteomic biomarkers with $O A$ in knee, hip and hand in 2 ways: 1) Cross-sectionally in all joints, where we analyzed severity of $\mathrm{OA}$ by adding up KL-scores of both joints (knee and hip $\mathrm{OA}$ ), and all joints of the left and right hand (total amount of joints=30); 2) Longitudinally in Knee and Hip, defining cases of progression of $\mathrm{OA}$ as an increase with at least 1 unit in KL-grade per person, excluding progressing from $\mathrm{KLO}$ to $\mathrm{KL} 1$. We analyzed the relationship with multivariate regression

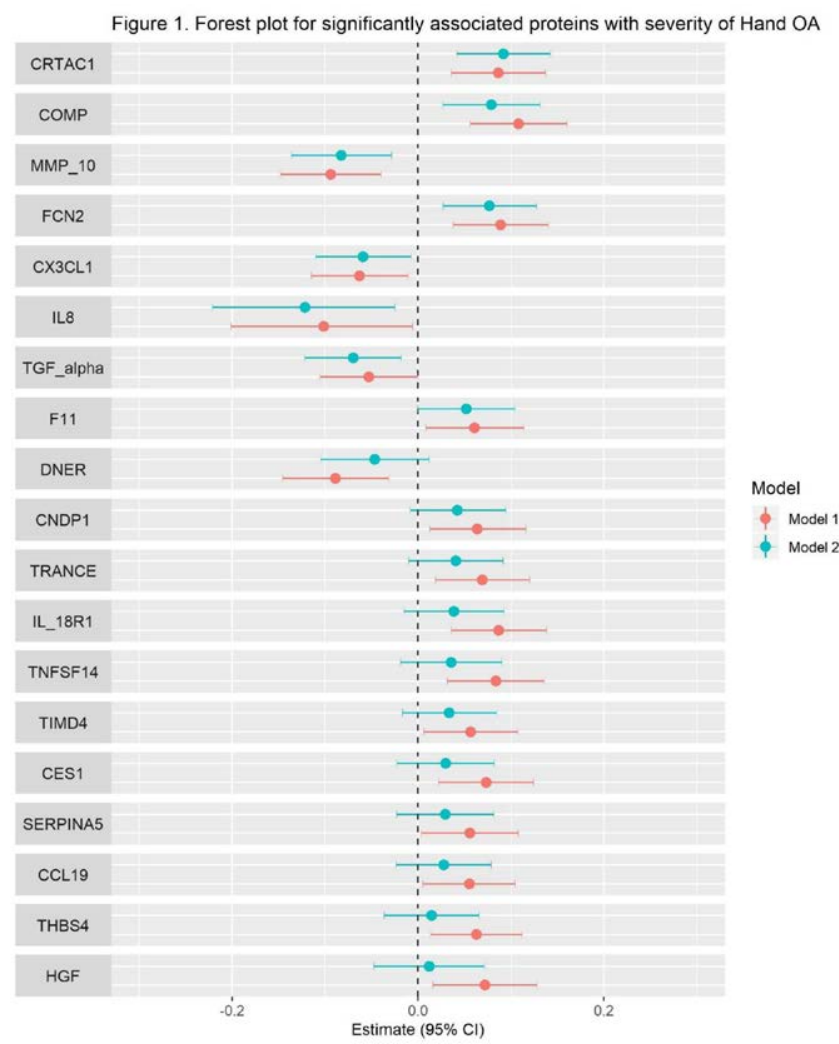

